\title{
Nitrogen Photofixation over III-Nitride Nanowires Assisted by Ruthenium Clusters of Low Atomicity
}

\author{
Lu Li $i^{+}$, Yichen Wang ${ }^{+}$, Srinivas Vanka, Xiaoyue Mu, Zetian Mi, ${ }^{*}$ and Chao-Jun Li*
}

\section{Dedicated to Professor David N. Harpp on the occasion of his 80th birthday}

\begin{abstract}
In many heterogeneous catalysts, the interaction of supported metal species with a matrix can alter the electronic and morphological properties of the metal and manipulate its catalytic properties. III-nitride semiconductors have a unique ability to stabilize ultra-small ruthenium (Ru) clusters (ca. $0.8 \mathrm{~nm}$ ) at a high loading density up to $5 w t \%$. n-Type III-nitride nanowires decorated with Ru sub-nanoclusters offer controlled surface charge properties and exhibit superior $U V$ and visible-light photocatalytic activity for ammonia synthesis at ambient temperature. A metal/semiconductor interfacial Schottky junction with a $0.94 \mathrm{eV}$ barrier height can greatly facilitate photogenerated electron transfer from III-nitrides to $R u$, rendering $R u$ an electron sink that promotes $N \equiv N$ bond cleavage, and thereby achieving low-temperature ammonia synthesis.
\end{abstract}

\section{$\boldsymbol{E}_{1}$} the proteins, amino acids, as well as DNA and RNA nucleotides of living organisms. ${ }^{[1]}$ Although nitrogen $\left(\mathrm{N}_{2}\right)$ is a major component of the atmosphere on earth, most organisms are unable to directly metabolize molecular $\mathrm{N}_{2}$ because of its inherent strong nonpolar triple bond. Therefore, $\mathrm{N}_{2}$ fixation by nitrogenase enzymes in certain bacteria probably ranks second only to photosynthesis as the most important biological process in nature. ${ }^{[2]}$ The first artificial conversion of atmospheric $\mathrm{N}_{2}$ to ammonia $\left(\mathrm{NH}_{3}\right)$ was successfully achieved in the early 20th century with ironbased catalysts - the so-called Haber-Bosch process-and is still applied all over the world today to contribute $500+$

[*] Dr. L. Li ${ }^{[+]}$Dr. X. Mu, Prof. C.-J. Li

Department of Chemistry and FQRNT Center for Green Chemistry and Catalysis, McGill University

801 Sherbrooke Street West, Montreal, QC, H3A OB8 (Canada)

E-mail: cj.li@mcgill.ca

Dr. L. Li, ${ }^{[+]}$Dr. Y. Wang, ${ }^{[+]}$S. Vanka, Prof. Z. Mi

Department of Electrical and Computer Engineering

McGill University

3480 University Street, Montreal, Québec H3A OE9 (Canada)

Prof. Z. Mi

Department of Electrical Engineering and Computer Science University of Michigan

1301 Beal Avenue, Ann Arbor, MI 48109-2122 (USA)

E-mail: ztmi@umich.edu

$\left.{ }^{+}\right]$These authors contributed equally to this work.

(2) Supporting information and the ORCID identification number(s) for

(D) the author(s) of this article can be found under:

https://doi.org/10.1002/anie.201703301. million tons of artificial fertilizers to global agriculture each year. Besides being a fertilizer, $\mathrm{NH}_{3}$ has also gained much attention as a potential hydrogen carrier since it possesses high gravimetric hydrogen density $(17.6 \mathrm{wt} \%)$ and is easily turned into a liquid for transportation. ${ }^{[3]}$ As one of the most widely used industrial resources, the bulk market price of $\mathrm{NH}_{3}$ is highly competitive with other hydrogen storage materials (at least an order of magnitude cheaper). However, the industrial $\mathrm{NH}_{3}$ synthesis process requires high temperatures $\left(500-600^{\circ} \mathrm{C}\right)$ and pressures $(20-50 \mathrm{MPa})$ to overcome the activation energy barrier of $\mathrm{N}_{2}$, and consumes more than $1 \%$ of the world's annual energy supply. ${ }^{[4]}$ To achieve energyefficient $\mathrm{NH}_{3}$ production, the development of a sustainable $\mathrm{N}_{2}$ fixation strategy under mild conditions has become one of the greatest challenges facing us today. ${ }^{[5]}$ More importantly, $\mathrm{NH}_{3}$ synthesis is an exothermic process [Eq. (1)] and therefore, the equilibrium conversion will increase with decreasing temperature.

$\mathrm{N}_{2}(\mathrm{~g})+3 \mathrm{H}_{2}(\mathrm{~g}) \rightarrow 2 \mathrm{NH}_{3}(\mathrm{~g}) \quad \Delta H_{(298 \mathrm{k})}=-92 \mathrm{~kJ} \mathrm{~mol}^{-1}$

Similar to the natural photosynthetic process, heterogeneous photocatalytic reactions usually take place under sunlight illumination at ambient temperature. ${ }^{[6]}$ Therefore, employing solar energy to activate inert $\mathrm{N}_{2}$ provides an ideal approach to both access $\mathrm{NH}_{3}$ under ambient conditions without requiring extra thermal energy input, and shift the equilibrium toward $\mathrm{NH}_{3}$ formation. The first photofixation of $\mathrm{N}_{2}$ was accomplished by Guth and Schrauzer based on a rutile-containing $\mathrm{TiO}_{2}$ semiconductor under UV irradiation. ${ }^{[7]}$ Other photoactive materials, such as non-metallic buckminsterfullerene $\left(\mathrm{C}_{60}\right),{ }^{[8]}$ UV-illuminated diamond, ${ }^{[9]}$ $\mathrm{Fe}_{2} \mathrm{Ti}_{2} \mathrm{O}_{7},{ }^{[10]} \mathrm{Au} / \mathrm{Nb} \mathrm{SrTiO}_{3},{ }^{[11]}$ and $\mathrm{BiOBr}^{[12]}$ are also capable of $\mathrm{N}_{2}$ fixation at room temperature and atmospheric pressure.

In spite of these important features and progressions, $\mathrm{N}_{2}$ photofixation still suffers from low efficiency because of the high-energy " $\mathrm{N}_{2}$ " intermediates $\left(\mathrm{N}_{2}{ }^{-}\right.$or $\left.\mathrm{N}_{2} \mathrm{H}\right),{ }^{[13]}$ as well as the poor interfacial electron transfer between the photocatalyst and adsorbed $\mathrm{N}_{2}$. For example, most pioneering works employed semiconductor oxide powders as photocatalysts. However, photogenerated electrons tend to recombine with simultaneously generated holes within a few nanoseconds rather than being captured by the surface adsorbed $\mathrm{N}_{2}$ and promoting $\mathrm{N} \equiv \mathrm{N}$ bond cleavage - the rate-determining step of $\mathrm{NH}_{3}$ synthesis. ${ }^{[14]}$ To overcome these limitations, we reason that well-designed nanosized semiconductors with strong electron-donating properties might offer an accessible kinetic pathway toward efficient photocatalytic $\mathrm{N}_{2}$ fixation. Further- 
more, the incorporation of optimized $\mathrm{Ru}$ cocatalysts is expected to reduce the activation barrier for $\mathrm{N}_{2}$ dissociation. ${ }^{[13]}$

Herein, we present that an efficient and stable photoreduction of $\mathrm{N}_{2}$ into $\mathrm{NH}_{3}$ can be achieved by depositing ultrasmall $\mathrm{Ru}$ clusters on the surfaces of $\mathrm{GaN}$ nanowires (NWs) with extremely high loading density (ca. $10^{17} \mathrm{~m}^{-2}$ ). While III-nitride semiconductors have been extensively utilized to fabricate electronic and optoelectronic devices, their photocatalytic activity has yet to be explored in depth. ${ }^{[15]}$ The controlled $\mathrm{n}$ - and p-type doping, tunable band gap, and inherent chemical stability of III-group nitrides render them particularly suitable electronically active supports for the photocatalytic $\mathrm{NH}_{3}$ synthesis reaction.

Catalyst-free gallium nitride $(\mathrm{GaN})$ NWs arrays were grown directly on silicon substrate by plasma-assisted molecular beam epitaxy (MBE) under $\mathrm{N}_{2}$-rich conditions (Supporting Information). Scanning electron microscopy (SEM; Figure 1a) and transmission electron microscopy (TEM; Figure $1 \mathrm{~b}$ ) images of the as-synthesized GaN NWs revealed that the NWs are about $80 \mathrm{~nm}$ in diameter and $800 \mathrm{~nm}$ in length, and are vertically aligned to the Si substrate, with the growth direction along the $c$-axis. ${ }^{[15 b]}$ The area density (the mass of GaN NWs per unit area) and specific surface area of the NWs were $0.1 \mathrm{mg} \mathrm{cm}^{-2}$ and $5.7 \mathrm{~m}^{2} \mathrm{~g}^{-1}$, respectively, which consist of $3 \%$ of the top $c$-plane and $97 \%$ of the lateral $m$-plane. Besides intrinsic GaN NWs, we also synthesized Ge-doped n-type and Mg-doped p-type GaN NWs, since the incorporation of tetravalent $\left(\mathrm{Ge}^{4+}\right)$ and divalent $\left(\mathrm{Mg}^{2+}\right)$ ions can significantly alter the Fermi-level position, surface band bending, and carrier transport properties of a $\mathrm{GaN}$ semiconductor. The electron and hole concentrations for the Ge-doped n-type and $\mathrm{Mg}$-doped p-type $\mathrm{GaN} \mathrm{NWs}$ were estimated to be in the order of $\mathrm{n}=5 \times 10^{18} \mathrm{~cm}^{-3}$ and

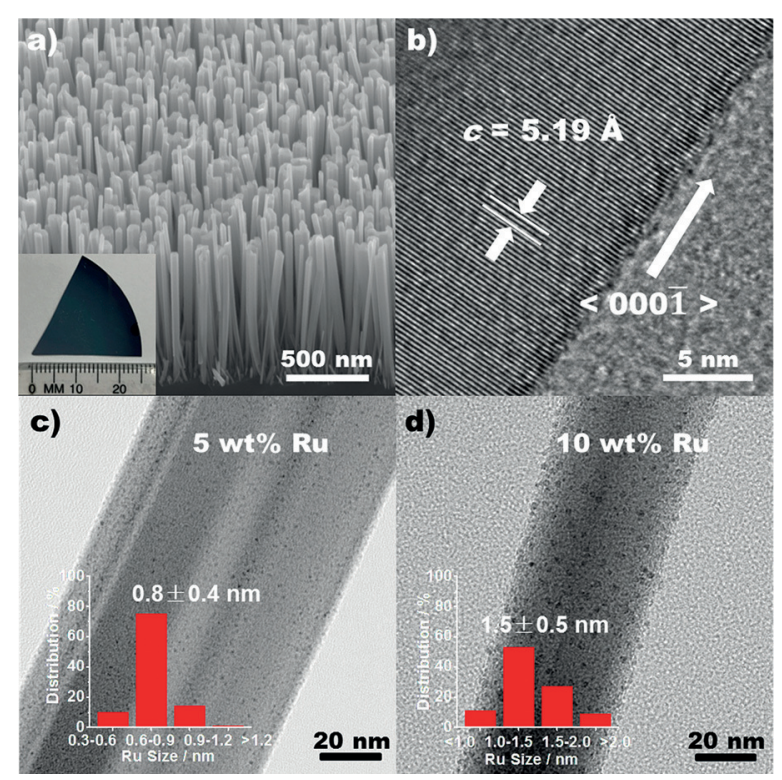

Figure 1. a) $45^{\circ}$ tilted SEM and b) TEM images of the as-synthesized GaN NWs. Inset (a) shows the sample size. TEM images of c) 5 wt \% Ru- and d) $10 \mathrm{wt} \%$ Ru-modified GaN NWs; inset plots (c) and (d) show diameter distributions of Ru clusters. $\mathrm{p}=1 \times 10^{18} \mathrm{~cm}^{-3}$, respectively, which can be controlled by tuning the effusion cell temperatures.

Supported $\mathrm{Ru}$ metal was introduced by impregnating assynthesized $\mathrm{GaN}$ NWs with a solution of $\mathrm{Ru}_{3}(\mathrm{CO})_{12}$ in dry tetrahydrofuran, followed by complete liberation of carbonyl groups at elevated temperature under vacuum (Supporting Information, Figure S1). ${ }^{[16]}$ Notably, GaN NWs stabilize a relatively high loading of $\mathrm{Ru}(5 \mathrm{wt} \%)$ in the form of finely dispersed sub-nanoclusters with a mean diameter of $0.8 \pm 0.4 \mathrm{~nm} \quad$ (average $20 \mathrm{Ru}$ atomscluster ${ }^{-1}$, Figure 1c). Although sub-nanoclusters are usually thermodynamically unstable, these Ru clusters are firmly anchored on the surface of $\mathrm{GaN}$ and were stable against agglomeration into large metal particles after heating at $350^{\circ} \mathrm{C}$ for $2 \mathrm{~h}$, indicating a strong interaction between $\mathrm{Ru}$ and the $\mathrm{GaN}$ lattice. The $\mathrm{Ru}$ species remain highly dispersed even if the loading is as high as $10 \mathrm{wt} \%$ (Figure $1 \mathrm{~d}$ ). The X-ray diffraction patterns (XRD; Supporting Information, Figure S2) suggest an ideal wurtzite crystal structure and there are no structural changes after loading with $\mathrm{Ru}$. The absence of any characteristic Ru peaks further confirms the small size of the resulting Ru clusters and the absence of agglomeration.

The photocatalytic $\mathrm{NH}_{3}$ synthesis performances of $\mathrm{GaN}$ materials with different doping types were tested at $10^{\circ} \mathrm{C}$ under UV irradiation from a $300 \mathrm{~W}$ xenon lamp (Supporting Information, Figures S3-S5). The catalyst was placed at the bottom of an airtight quartz reactor, a vacuum established, and a mixture of $\mathrm{H}_{2}$ and $\mathrm{N}_{2}$ gases introduced (600 $\mu \mathrm{mol}, 75 \%$ $\mathrm{H}_{2}, 25 \% \mathrm{~N}_{2}$ ). As shown in Figure $2 \mathrm{a}$ and Table $\mathrm{S} 1$ (Supporting Information), the n-type GaN NWs exhibited significantly enhanced photocatalytic activity for $\mathrm{NH}_{3}$ generation compared with the non-doped NWs. On the other hand, the activity of p-type GaN NWs was slightly reduced. Besides GaN NWs, GaN powders (designated as GaN-P) also showed substantial activity. Using a series of UV cut-out filters, we determined that the minimum photon energy required to drive this reaction over all GaN samples corresponds to a wavelength of $360 \mathrm{~nm}$. No conversion was detected in darkness. A control experiment using pure $\mathrm{H}_{2}$ instead of a mixture of $\mathrm{H}_{2}$ and $\mathrm{N}_{2}$ did not generate $\mathrm{NH}_{3}$, confirming that the $\mathrm{NH}_{3}$ produced originated, not from GaN decomposition, but from the photocatalytic reduction of $\mathrm{N}_{2}$ gas.

$\mathrm{Ru}$ metal promotes $\mathrm{N} \equiv \mathrm{N}$ bond cleavage efficiently by receiving electrons from the $3 \sigma_{\mathrm{g}}$ bonding orbitals of adsorbed $\mathrm{N}_{2}$ molecules and donating electrons back to the $1 \pi_{\mathrm{g}}{ }^{*}$ antibonding orbitals of $\mathrm{N}_{2} \cdot{ }^{[17]}$ To further enhance chargecarrier extraction and provide additional active sites for $\mathrm{N}_{2}$ activation, metallic $\mathrm{Ru}$ cocatalysts were deposited on the GaN samples. As shown in Figure 2b, catalytic efficiency was significantly enhanced by the introduction of $\mathrm{Ru}$ metal. The $\mathrm{NH}_{3}$ synthesis rate of Ru@n-GaN NWs increased with the $\mathrm{Ru}$ loading amount and reached a maximum at $5 \mathrm{wt} \% \mathrm{Ru}$ deposition, over nine times that of bare n-GaN NWs. When the $\mathrm{Ru}$ loading exceeded $5 \mathrm{wt} \%$, an obvious reduction in activity was observed, which could be attributed to decreased utilization efficiency of $\mathrm{Ru}$ atoms with the increasing cluster size.

To gain a better understanding of the nature of the catalytic active sites, Ru modified n-GaN NWs, Ru*@n-GaN 


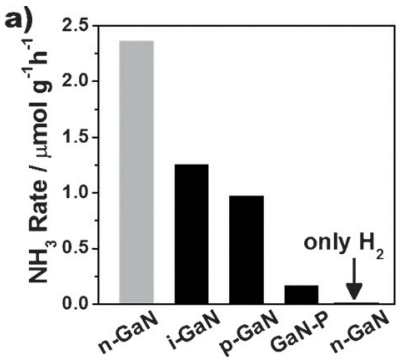

c)

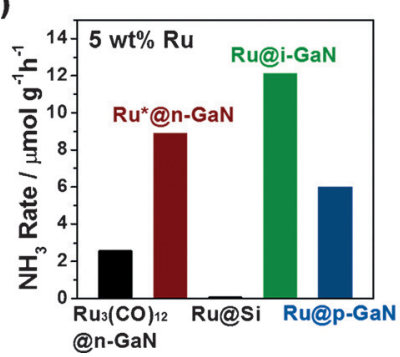

b)

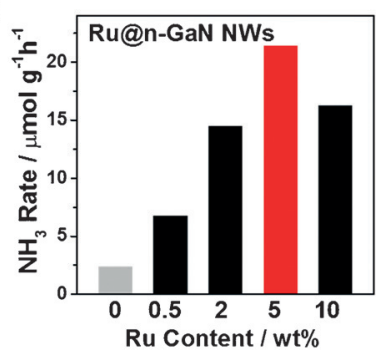

d)

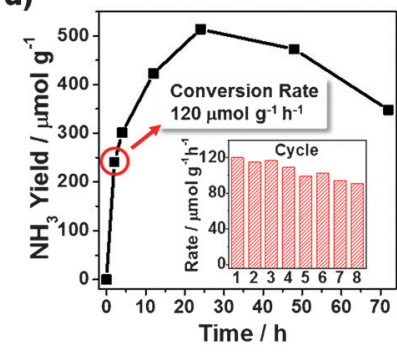

Figure 2. $\mathrm{NH}_{3}$ generation rate over a) pure $\mathrm{GaN}$ materials with different doping levels and forms (24 h), b) Ru-modified n-GaN NWs with different loading levels ( $24 \mathrm{~h}$ ), and c) various supports with $5 \mathrm{wt} \% \mathrm{Ru}$ loading $(24 \mathrm{~h})$. d) Plots of $\mathrm{NH}_{3}$ release as a function of time over the optimized 5 wt \% Ru-loaded n-GaN NWs under UV irradiation. Inset: reusability of Ru@n-GaN (2 h for each cycle). Reaction conditions: GaN NWs (0.35 mg), GaN powders (0.35 mg), Ru@GaN (0.35 mg); $290-380 \mathrm{~nm}$ UV irradiation, intensity $=7.5 \mathrm{~mW} \mathrm{~cm}^{-2}$.

(fabricated by decomposition of $\mathrm{RuCl}_{3}$ precursor on $\mathrm{n}-\mathrm{GaN}$ ) and $\mathrm{Ru}_{3}(\mathrm{CO})_{12} @ \mathrm{n}-\mathrm{GaN}\left(\mathrm{Ru}_{3}(\mathrm{CO})_{12}\right.$ modified n-GaN NWs) were prepared. It was found that $\mathrm{Ru}_{3}(\mathrm{CO})_{12}$ incorporation has a negligible effect on the catalytic activity compared to the bare $\mathrm{n}-\mathrm{GaN}$ NWs (Figure 2c), likely because $\mathrm{Ru}$ atoms in $\mathrm{Ru}_{3}(\mathrm{CO})_{12}$ are coordinatively saturated and thus unavailable for $\mathrm{N}_{2}$ insertion. On the other hand, although the content, shape, and size of $\mathrm{Ru}$ species in $\mathrm{Ru} * @ \mathrm{n}-\mathrm{GaN}$ are similar to those in Ru@n-GaN, as confirmed by TEM, XRD, and X-ray photoelectron spectroscopy (XPS), the photoactivity of Ru*@n-GaN was much lower than that of Ru@n-GaN under the same reaction conditions (Figure 2c). This phenomenon implies that the chloride ions remaining on the $\mathrm{Ru}$ metal surface act as a poison against $\mathrm{NH}_{3}$ synthesis because the active sites available for hydrogen chemisorption are blocked by chloride ions. ${ }^{[18]}$ Consequently, our results show that the $\mathrm{Ru}$ cocatalyst is quite sensitive and employing $\mathrm{Cl}$-free $\mathrm{Ru}$ precursors is critical to achieve the best catalytic performances.

The electronic properties of the semiconductor have a fundamental influence on the catalytic activity of supported metal species. ${ }^{[6,19]}$ As shown in Figures $2 \mathrm{~b}$ and $2 \mathrm{c}$, the $\mathrm{NH}_{3}$ generation rate of $\mathrm{Ru} @ \mathrm{n}-\mathrm{GaN}$ is significantly higher than $\mathrm{Ru} @ \mathrm{p}-\mathrm{GaN}$. An average $\mathrm{NH}_{3}$ generation rate of $120 \mu \mathrm{molh}^{-1} \mathrm{~g}^{-1}$ was achieved after $2 \mathrm{~h}$ UV irradiation using $0.35 \mathrm{mg}$ of the optimized Ru@n-GaN NWs with $5 \mathrm{wt} \% \mathrm{Ru}$ (Figure $2 \mathrm{~d}$ ) at $10^{\circ} \mathrm{C}$, corresponding to $2400 \mathrm{umol} \mathrm{h}^{-1} \mathrm{~g}^{-1}$ based on $\mathrm{Ru}\left(\mathrm{TOF}=0.24 \mathrm{~h}^{-1}\right)$. Compared with previously published results, ${ }^{[20]}$ the activity of Ru@n-GaN is enhanced by a factor of five under similar conditions around room temperature. The $\mathrm{NH}_{3}$ concentration reached a maximum after $24 \mathrm{~h}$ of

irradiation and decreased gradually when the reaction time was prolonged. Decomposition of $\mathrm{NH}_{3}$ became dramatic if the produced $\mathrm{NH}_{3}$ was not removed from the reactor promptly. The reusability of $\mathrm{Ru} @ \mathrm{n}-\mathrm{GaN}$ for $\mathrm{NH}_{3}$ synthesis was tested (Figure $2 \mathrm{~d}$ inset) and the catalytic results showed that the Ru@n-GaN catalyst can be used repeatedly after eight catalytic runs with only slight deactivation. The crystal structure and morphology of the catalyst sample remained intact after prolonged reactivity, as judged by the XRD, SEM, and TEM results (Supporting Information, Figure S6). A control experiment revealed that the reaction does not proceed at all in the absence of GaN matrix (exemplified using pure $\mathrm{Si}$ wafer as a support).

In the case of Ru@n-GaN, electrons flow from n-GaN NWs into Ru sub-nanoclusters on contact, since the Fermi level of $\mathrm{n}-\mathrm{GaN}$ NWs is above that of Ru metal (Figure $3 \mathrm{a}$ ). a)

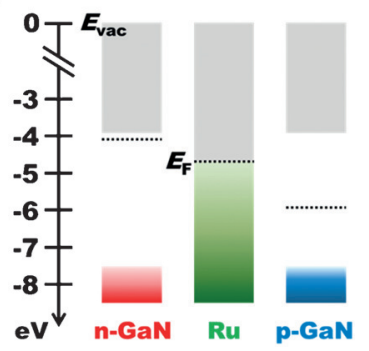

b)

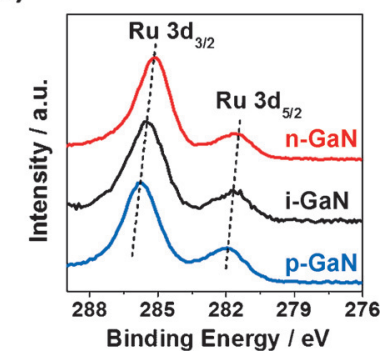

Figure 3. a) Comparison of the energy band diagram and $E_{\mathrm{F}}$ in n-type GaN NWs, Ru metal, and p-type GaN NWs. $E_{\mathrm{vac}}=$ vacuum level. b) XPS spectra of Ru 3d for the different Ru-modified catalysts.

Consequently, a depletion layer is established at the interface, where the $\mathrm{Ru}$ metal is negatively charged and the semiconductor is positively charged near the surface (Supporting Information, Figure S7a). The influence of this electrostatic induction could spread throughout the Ru clusters because of their ultra-small sizes $(<1 \mathrm{~nm})$. On the other hand, a reduction of local electron density at the $\mathrm{Ru}$ cluster is induced by the opposite electric field in Ru@p-GaN (Supporting Information, Figure S7b). The XPS results clearly indicate that the Ru3d peaks of Ru@n-GaN are negatively shifted $(285.2 \mathrm{eV})$ compared to the binding energies of $\mathrm{Ru}$ on i-GaN (285.5 eV) and p-GaN (285.8 eV; Figure 3b). These results suggest that n-type GaN NWs could function as an efficient electron donor to produce $\mathrm{Ru}$ species with high electron density, which can act as Lewis base sites that are highly beneficial to the reduction of $\mathrm{N}_{2}$.

Since the work function of $\mathrm{Ru}$ metal $\left(\Phi_{M}=4.7 \mathrm{eV}\right)$ is higher than that of the n-type GaN semiconductor $\left(\Phi_{S}=\right.$ $4.1 \mathrm{eV}),{ }^{[21]}$ a resulting upward band bending will be formed at the interface to create a potential barrier, known as the Schottky barrier. ${ }^{[22]}$ As illustrated in Figure $4 \mathrm{a}$, the formed Schottky barrier serves as an irreversible electron sink to trap the photoinduced electrons from n-GaN NWs under photoexcitation; remarkably, electron-hole recombination is prevented and enhanced photocatalytic performance often results. Based on the Schottky-Mott theory, the barrier height $\left(\Phi_{S B}\right)$ follows the rule $\left(\Phi_{S B}=\Phi_{M}-\chi_{S}\right)$, where $\chi_{\mathrm{S}}$ is the 
a)
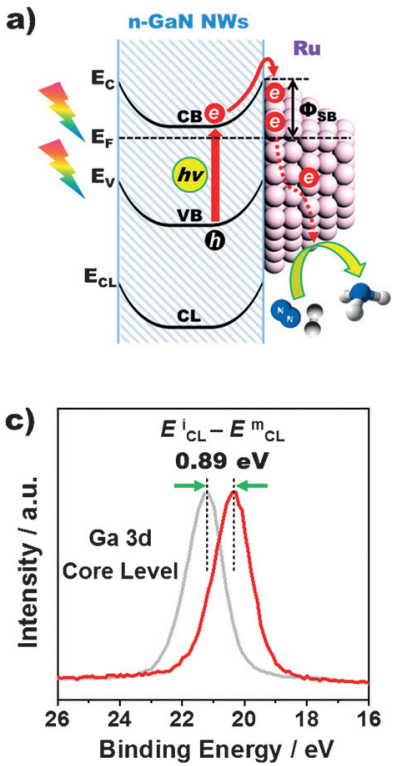

b)
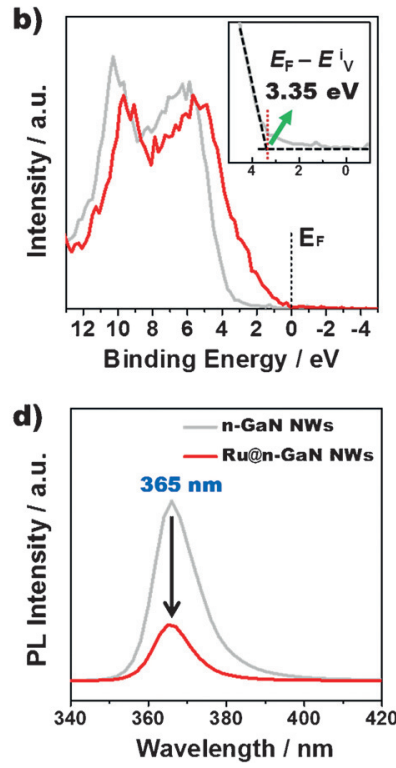

Figure 4. a) Schematic for the formation of the Schottky barrier between n-type GaN NWs and metallic Ru clusters. b) XPS valence band spectra, c) Ga 3d core-level XPS spectra, and d) PL spectra of $\mathrm{n}-\mathrm{GaN}$ NWs before (gray curve) and after the deposition of Ru (red curve). Inset (b): the near- $E_{\mathrm{F}}$ region and valence band maximum position $E_{F}-E_{V}^{i}$ of pure n-GaN NWs.

electron affinity of n-GaN NWs. However, in case of lowdimensional systems, the height of the Schottky barrier depends, not only on the work functions, but also on the annealing temperature, image-force effect, and the existence of Fermi-level pinning by surface states. ${ }^{[23]}$ To determine the barrier height value $\left(\Phi_{S B}\right)$ of Ru sub-nanoclusters on n-GaN NWs, a series of XPS spectra were measured according to Equation (2), ${ }^{[24]}$

$\Phi_{S B}=E_{\mathrm{g}}-\left(E_{\mathrm{F}}-E_{\mathrm{V}}^{i}\right)+\left(E_{\mathrm{CL}}^{i}-E_{\mathrm{CL}}^{m}\right)$

where $E_{\mathrm{g}}(3.4 \mathrm{eV})$ is the band gap of $\mathrm{n}-\mathrm{GaN} \mathrm{NWs}, E_{\mathrm{F}}$ is the Fermi level, $E_{\mathrm{V}}^{i}$ is the initial binding energy of the valence band maximum of the fresh $\mathrm{n}-\mathrm{GaN}$ NWs, $E_{\mathrm{CL}}^{i}$ is the initial binding energy of the fresh n-GaN NWs core-level peak and $E^{m}{ }_{C L}$ is the binding energy of the n-GaN NWs core-level peak after metal deposition. All binding energies are measured relative to the Fermi energy $\left(E_{\mathrm{F}}=0 \mathrm{eV}\right)$. As shown in Figure $4 \mathrm{~b}$, the near-surface $E_{\mathrm{F}}-E_{\mathrm{V}}^{i}$ of the intact n-GaN NWs was measured to be $3.35 \mathrm{eV}$, which decreased distinctly following $\mathrm{Ru}$ deposition, indicating an increase in upward band bending. The precise determination of $\Phi_{S B}$ is calculated based on the differences in the Ga $3 \mathrm{~d}$ core-level energies. A core-level shift of $0.89 \mathrm{eV}\left(E_{\mathrm{CL}}^{i}-E^{m}{ }_{\mathrm{CL}}\right)$ towards the lower binding energy occurs with $\mathrm{Ru}$ deposition, as demonstrated by Figure $4 \mathrm{c}$. Consequently, the Schottky barrier height $\Phi_{S B}$ was calculated to be $0.94 \mathrm{eV}$, according to Equation (2).

Figure $4 \mathrm{~d}$ shows the room-temperature photoluminescence (PL) spectrum of $\mathrm{n}-\mathrm{GaN}$ NWs before and after $\mathrm{Ru}$ deposition. Although the PL bands are both located at about $365 \mathrm{~nm}$, corresponding to the $\mathrm{GaN}$ band gap of $3.4 \mathrm{eV}$, the peak intensity of $\mathrm{Ru} @ \mathrm{n}-\mathrm{GaN}$ is much weaker than that of

pure n-GaN under the same measurement conditions. The reduction in PL intensity after $\mathrm{Ru}$ deposition further demonstrated that the formed Schottky barrier can act as an electron trap to improve photogenerated electron-hole separation.

The band gap of GaN can shift from the UV to the visible region by incorporating In. ${ }^{[15 c]}$ To further realize the visiblelight photoactivity of III-nitrides towards $\mathrm{NH}_{3}$ synthesis, we have designed and synthesized $\mathrm{InGaN} / \mathrm{GaN}$ nanowire arrays on $\mathrm{Si}(111)$ substrate by MBE (Figures $5 \mathrm{a}$; Supporting Information, Figure S8). ${ }^{[25]}$ Detailed structure and elemental dis-
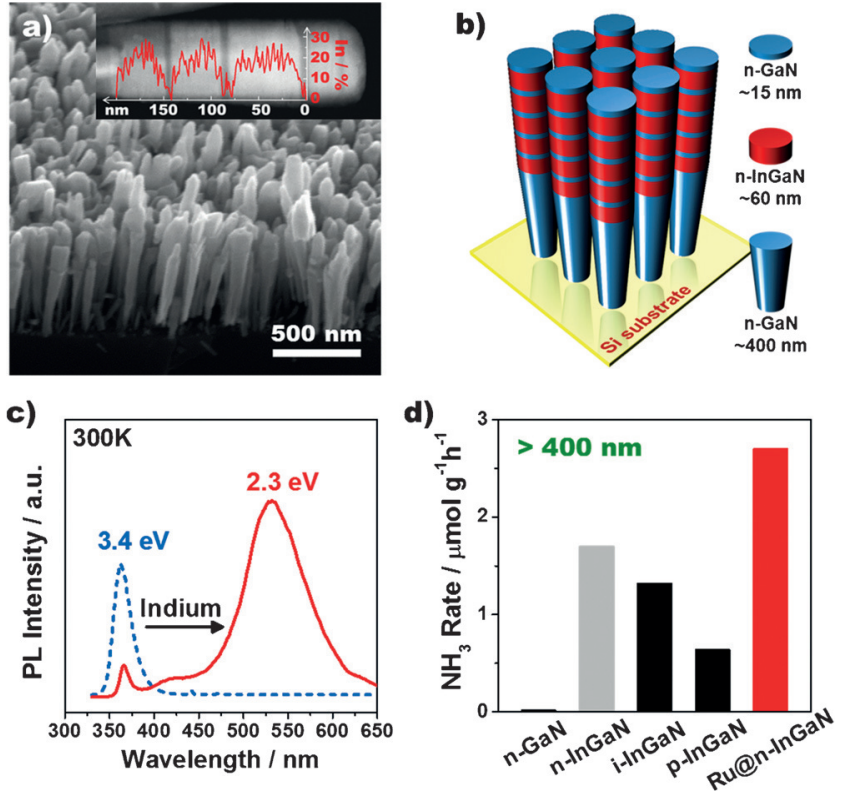

Figure 5. a) $\mathrm{A} 45^{\circ} \mathrm{C}$ tilted SEM image of as-grown InGaN/GaN NWs on Si (111) substrate. Inset: STEM-HAADF image of a single InGaN/ $\mathrm{GaN}$ nanowire and a line-profile analysis for the distribution of In content. b) Schematic for the InGaN/GaN nanowire structure showing five InGaN nanowire segments on a GaN nanowire template. c) Roomtemperature PL spectrum of as-synthesized InGaN/GaN NWs. d) $\mathrm{NH}_{3}$ generation rate over various III-nitride materials under visible-light irradiation. Conditions: III-nitride (0.35 mg), Ru@InGaN/GaN NWs (5 wt\%); visible-light irradiation, intensity $=20 \mathrm{~mW} \mathrm{~cm}{ }^{-2}, 24 \mathrm{~h}$.

tribution were characterized using high-angle annular darkfield (HAADF)/scanning transmission electron microscopy (STEM) and energy-dispersive X-ray scanning (EDXS) analysis (Figure 5a inset), revealing the existence of the segment structure and the distribution of the In components in the NWs. As illustrated in Figures $5 \mathrm{~b}$ and Figure S5 (Supporting Information), ${ }^{[26]}$ five segments of InGaN ternary wires were incorporated along the growth direction of $\mathrm{GaN}$ NWs to suppress In phase separation. The height of each InGaN/GaN segment was controlled by the growth time (ca. $2.5 \mathrm{~nm} \mathrm{~min}^{-1}$ ), and further doping with $\mathrm{Ge}^{4+}$ or $\mathrm{Mg}^{2+}$ ions as n-type or p-type dopants was possible. The room-temperature PL spectrum (Figure $5 \mathrm{c}$ ) of InGaN/GaN NWs clearly shows a single band-to-band optical emission peak at approximately $531 \mathrm{~nm}$, corresponding to an InGaN band gap of $2.34 \mathrm{eV}$ with an average In composition of about $25 \% .^{[27]}$ Figure $5 \mathrm{~d}$ gave 
the photocatalytic results of various InGaN/GaN samples for $\mathrm{NH}_{3}$ synthesis under visible-light irradiation $(>400 \mathrm{~nm})$ at room temperature. Compared with the p-type and intrinsic samples, $\mathrm{n}-\mathrm{InGaN} / \mathrm{n}-\mathrm{GaN}$ nanowire arrays exhibit the highest activity (designated as $\mathrm{n}-\mathrm{InGaN}$ ), which could be further improved by the deposition of $5 \mathrm{wt} \% \mathrm{Ru}$ (Supporting Information, Figure S9). In contrast, pure n-GaN without incorporated In did not show any activity under the same conditions.

In summary, a promising photoinduced approach to access $\mathrm{NH}_{3}$ synthesis in ambient conditions was realized over $\mathrm{Ru}-$ supported III-nitride hybrids. The GaN NWs exhibit superior ability to stabilize ultra-small $\mathrm{Ru}$ sub-nanoclusters with high loading density. The catalytic activity of the loaded $\mathrm{Ru}$ is very sensitive to its electronic property, the $\mathrm{Cl}$-free precursor, and support. We have demonstrated that $\mathrm{Ge}^{4+}$ doped n-type $\mathrm{GaN}$ NWs could act as an efficient electron donor for the $\mathrm{Ru}$ cocatalyst, forming a Schottky barrier junction and resulting in partially negatively charged Ru species with an enhanced catalytic performance. Incorporation of In into the GaN NWs tuned the $\mathrm{N}_{2}$ fixing photocatalyst to the visible-light regime.

\section{Acknowledgements}

This work was financially supported by the Canada Research Chair (Tier 1) foundation, the Natural Sciences and Engineering Research Council of Canada, Fonds de recherche du Québec - Nature et Technologies, Canada Foundation for Innovation (CFI), and McGill University.

\section{Conflict of interest}

The authors declare no conflict of interest.

Keywords: ammonia synthesis - metal nitrides - photocatalysis . ruthenium clusters $\cdot$ Schottky barrier

How to cite: Angew. Chem. Int. Ed. 2017, 56, 8701-8705 Angew. Chem. 2017, 129, 8827-8831

[1] I. Čorić, B. Q. Mercado, E. Bill, D. J. Vinyard, P. L. Holland, Nature 2015, 526, $96-99$

[2] B. E. Smith, Science 2002, 297, 1654-1655.

[3] W. Zheng, T. P. Cotter, P. Kaghazchi, T. Jacob, B. Frank, K. Schlichte, W. Zhang, D. S. Su, F. Schüth, R. Schlögl, J. Am. Chem. Soc. 2013, 135, 3458-3464.

[4] J. W. Erisman, M. A. Sutton, J. Galloway, Z. Klimont, W. Winiwarter, Nat. Geosci. 2008, 1, 636-639.

[5] Y. Nishibayashi, Inorg. Chem. 2015, 54, 9234-9247.

[6] a) L. Li, G.-D. Li, C. Yan, X.-Y. Mu, X.-L. Pan, X.-X. Zou, K.-X Wang, J.-S. Chen, Angew. Chem. Int. Ed. 2011, 50, 8299-8303; Angew. Chem. 2011, 123, 8449-8453; b) L. Li, Y.-Y. Cai, G.-D Li, X.-Y. Mu, K.-X. Wang, J.-S. Chen, Angew. Chem. Int. Ed.
2012, 51, 4702-4706; Angew. Chem. 2012, 124, 4780-4784; c) L. Li, X. Mu, W. Liu, Z. Mi, C. J. Li, J. Am. Chem. Soc. 2015, 137, $7576-7579$.

[7] G. N. Schrauzer, T. D. Guth, J. Am. Chem. Soc. 1977, 99, 71897193.

[8] Y. Nishibayashi, M. Saito, S. Uemura, S.-i. Takekuma, H. Takekuma, Z.-i. Yoshida, Nature 2004, 428, 279-280.

[9] D. Zhu, L. Zhang, R. E. Ruther, R. J. Hamers, Nat. Mater. 2013 , $12,836-841$.

[10] O. Rusina, A. Eremenko, G. Frank, H. P. Strunk, H. Kisch, Angew. Chem. Int. Ed. 2001, 40, 3993-3995; Angew. Chem. 2001, 113, 4115 - 4117.

[11] T. Oshikiri, K. Ueno, H. Misawa, Angew. Chem. Int. Ed. 2014, 53, 9802-9805; Angew. Chem. 2014, 126, 9960-9963.

[12] H. Li, J. Shang, Z. Ai, L. Zhang, J. Am. Chem. Soc. 2015, 137, $6393-6399$.

[13] K. Honkala, A. Hellman, I. N. Remediakis, A. Logadottir, A. Carlsson, S. Dahl, C. H. Christensen, J. K. Nørskov, Science 2005, 307, $555-558$

[14] M. Kitano, Y. Inoue, Y. Yamazaki, F. Hayashi, S. Kanbara, S. Matsuishi, T. Yokoyama, S.-W. Kim, M. Hara, H. Hosono, Nat. Chem. 2012, 4, 934-940.

[15] a) D. Wang, A. Pierre, M. G. Kibria, K. Cui, X. Han, K. H. Bevan, H. Guo, S. Paradis, A.-R. Hakima, Z. Mi, Nano Lett. 2011, 11, 2353-2357; b) L. Li, S. Fan, X. Mu, Z. Mi, C.-J. Li, J. Am. Chem. Soc. 2014, 136, 7793-7796; c) M. G. Kibria, F. A. Chowdhury, S. Zhao, B. AlOtaibi, M. L. Trudeau, H. Guo, Z. Mi, Nat. Commun. 2015, 6, 6797.

[16] D. K. Chakrabarty, A. Joshi, S. Unnikrishnan, P. D. Prabhawalkar, React. Kinet. Catal. Lett. 1984, 26, 143-147.

[17] C. N. R. Rao, G. Ranga Rao, Surf. Sci. Rep. 1991, 13, 223-263.

[18] a) S. Murata, K.-I. Aika, Appl. Catal. A 1992, 82,1-12; b) K. Lu, B. J. Tatarchuk, J. Catal. 1987, 106, 166-175.

[19] S. Schäfer, S. A. Wyrzgol, R. Caterino, A. Jentys, S. J. Schoell, M. Hävecker, A. Knop-Gericke, J. A. Lercher, I. D. Sharp, M. Stutzmann, J. Am. Chem. Soc. 2012, 134, 12528-12535.

[20] H. Zeng, S. Terazono, T. Tanuma, Catal. Commun. 2015, 59, 40 44.

[21] J. S. Foresi, T. D. Moustakas, Appl. Phys. Lett. 1993, 62, 28592861.

[22] Z. Zhang, J. T. Yates, Chem. Rev. 2012, 112, 5520-5551.

[23] S. M. Sze, K. K. Ng, Physics of Semiconductor Devices, 3rd ed., Wiley, New York, 2007.

[24] a) E. A. Kraut, R. W. Grant, J. R. Waldrop, S. P. Kowalczyk, Phys. Rev. Lett. 1980, 44, 1620-1623; b) J. R. Waldrop, R. W. Grant, Appl. Phys. Lett. 1988, 52, 1794-1796; c) K. M. Tracy, P. J. Hartlieb, S. Einfeldt, R. F. Davis, E. H. Hurt, R. J. Nemanich, J. Appl. Phys. 2003, 94, 3939-3948.

[25] B. AlOtaibi, X. Kong, S. Vanka, S. Y. Woo, A. Pofelski, F. Oudjedi, S. Fan, M. G. Kibria, G. A. Botton, W. Ji, H. Guo, Z. Mi, ACS Energy Lett. 2016, 1, 246-252.

[26] H. P. T. Nguyen, S. Zhang, K. Cui, X. Han, S. Fathololoumi, M. Couillard, G. A. Botton, Z. Mi, Nano Lett. 2011, 11, 1919-1924.

[27] P. G. Moses, C. G. V. de Walle, Appl. Phys. Lett. 2010, 96, 021908.

Manuscript received: March 29, 2017

Revised manuscript received: May 30, 2017

Accepted manuscript online: June 9, 2017

Version of record online: June 23, 2017 